\title{
dx.doi.org/10.17488/RMIB.38.1.16
}

\section{Characterizing the hippocampal theta's response to carbachol; using a complete septo-hippocampal preparation}

\section{Caracterización de la respuesta theta del hipocampo al carbacol en una preparación septo-hipocámpica completa}

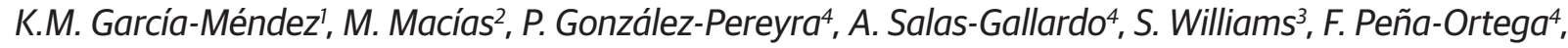 \\ S. Mondragón-Rodríguez ${ }^{3,4,5}$ \\ 'University of Celaya, Celaya, Guanajuato, México. \\ ²Benemérita Universidad Autónoma de Puebla, Puebla, México. \\ ${ }^{3}$ Douglas Hospital Research Center, Department of Psychiatry, McGill University, Montreal, Quebec, Canada. \\ ${ }^{4}$ Developmental Neurobiology and Neurophysiology, Institute of Neurobiology, UNAM, Querétaro, México. \\ ${ }^{5}$ CONACyT-National Concil for Science and Technology, México, México.
}

\section{RESUMEN}

El presente estudio describe el análisis farmacológico de los efectos de carbacol, un agonista colinérgico, sobre la actividad theta del hipocampo. Sabiendo que esta actividad está críticamente relacionada con la función cognitiva y alterada en pacientes con neurodegeneración, los esfuerzos farmacológicos destinados a modular directamente la actividad theta del hipocampo se vuelven de gran importancia. En una preparación completa que contiene la región septal media conectada al hipocampo, desarrollada recientemente, $1 \mu \mathrm{M}$ de carbacol provocó un incremento significativo a nivel de potencia en la actividad theta del hipocampo. Las concentraciones menores de1 $\mu \mathrm{M}$ y mayores a $2 \mu \mathrm{M}$ causaron una reducción significativa en la potencia de la actividad theta. Los efectos del carbacol fueron completamente bloqueados con la escopolamina, antagonista colinérgico. A nivel experimental, es la primera vez que se evalúa la acción directa de un agonista colinérgico en la vía septo-hipocámpica completamente aislada. Sin embargo, el carbacol como agonista colinérgico es un fármaco que presenta cierto nivel de respuesta inespecífica. Es por eso que para corregir esta limitante experimental, se utilizó escopolamina (antagonista colinérgico) lo que nos permitió corroborar los efectos sobre la vía colinérgica. En resumen, nuestros estudios electrofisiológicos demostraron un intervalo de concentración eficaz del carbacol que modula específicamente la actividad theta del hipocampo.

PALABRAS CLAvE: Theta, hipocampo, potencia y carbacol. 


\section{ABSTRACT}

The present study describes the pharmacological analysis of the effects of carbachol, a cholinergic agonist, on hippocampal theta activity. Knowing that this activity is critically related to cognitive function and altered in patients with neurodegeneration, pharmacological efforts aiming to directly modulate hippocampal theta activity becomes of central importance. In a recently developed complete septo-hippocampal preparation, carbachol elicited significant theta power enhancement with $1 \mu \mathrm{M}$. Concentrations under $1 \mu \mathrm{M}$ and over $2 \mu \mathrm{M}$ carbachol caused significant reduction in the power of hippocampal theta activity. Carbachol effects were completely blocked with the cholinergic antagonist scopolamine. At the experimental level, it is the first time the direct action of a cholinergic agonist is evaluated in the septo-hippocampal pathway completely isolated. However, carbachol as a cholinergic agonist is a drug with a certain level of nonspecific response. That is why to correct this experimental limitation, we used scopolamine (cholinergic antagonist) which allowed us to corroborate the effects on the cholinergic pathway. In summary, electrophysiological assays demonstrated an effective concentration range of carbachol specifically modulating hippocampal theta activity.

KEYwORDS: Theta, hippocampus, modulation and carbachol.

\section{Correspondencia}

DESTINATARIO: Siddhartha Mondragón-Rodríguez, Ph.D.

INSTITUCIÓN: Departamento de Neurobiología

del Desarrollo y Neurofisiología, Instituto de

Neurobiología, Universidad Nacional Autónoma de

México

DIRECCIÓN: Blvd. Juriquilla \#3001, Col. Juriquilla, C.P.

76230, Santiago de Querétaro, Querétaro, México

CORREO ELECTRÓNICO: sidmonrod@gmail.com

\section{Fecha de recepción:}

14 de octubre de 2016

Fecha de aceptación:

24 de noviembre de 2016 


\section{INTRODUCTION}

Theta rhythms of the hippocampus are proposed to be essential for learning and memory ${ }^{[1]}$. Until recently, theta oscillations between frequencies of 2 and $12 \mathrm{~Hz}$ were thought to be generated primarily by the entorhinal input, CA3 Schaffer collaterals and voltage dependent $\mathrm{Ca}^{2+}$ currents in pyramidal cells ${ }^{[2]}$. However, recent findings showed that besides the inputs from multiple brain areas, intrinsic theta oscillators within the hippocampus are critical for theta rhythm generation $^{[3]}$. A main contributor for theta generation and modulation is the medial septum and diagonal band of Broca (MS-DBB), another important input to the hippocampus $^{[4]}$. The MS-DBB contains cholinergic, GABAergic, and glutamatergic neurons directly projecting the hippocampus ${ }^{[4,5]}$. It has been suggested that a fine interplay exists between the external inputs regulating the modulation of the amplitude (power) and frequency in hippocampal theta rhythms ${ }^{[5,6]}$. Although it remains mechanistically unclear how network activity relates to memory, it has been suggested that the changes in theta frequency and power participate and promote in the synchronization of hippocampal activity, and this phenomena could partially explain the mechanism behind memory formation and consolidation ${ }^{[7]}$. In this regard, such changes in oscillatory theta activity are primarily dependent on cholinergic afferents originating in the MS-DBB ${ }^{[8]}$. For example, in anesthetized and freely moving mice, it was found that stimulation of cholinergic neurons enhances theta rhythm and suppresses peri-theta frequency bands, therefore increasing both power and coherence of theta oscillations ${ }^{[8]}$. In this vein, the role of the pedunculopontine tegmental nucleus (PPN) was evaluated due to its cholinergic component. In the present study, it was found that the PPN opioid system can enhance or suppress the carbachol (a cholinergic agonist) induced hippocampal theta activity depending on the actual level of PPN activation ${ }^{[9]}$. This data suggests that the potential role of cholinergic activation relays in synchronizing hippocampal activity ${ }^{[9]}$.
Aiming to further study this hypothesis, by using the technique of intraseptal microinfusion of carbachol, total power increase in the theta band was found ${ }^{[4]}$. Overall, it is clear that hippocampal theta activity induced by the cholinergic agonist i.e. carbachol, contributes to enhancing power and in less proportion, synchronization of the hippocampal theta activity; however, all of the previous experiments have been performed in utilizing the in-vivo experimental approach. This particular brings the issue of keeping cholinergic inputs from multiple brain areas and therefore making difficult to dissect the specific contribution of septo-cholinergic neurons projecting directly to the hippocampus. Aiming to overcome this problem we explored the effect of the cholinergic agonist carbachol in the complete septo-hippocampal preparation $^{[3]}$. The preparation is capable of self generating hippocampal activity in the theta frequency band (2-10 Hz) and most importantly, comprises the medial septum with all the afferents connected to the hippocampus, including all the septo-hippocampal cholinergic circuitry ${ }^{[3]}$. Here, we demonstrated that carbachol in a dose dependent manner influences the power of hippocampal theta activity; therefore, suggesting that the main effect of septo-cholinergic neurons relays in theta power modulation.

\section{MATERIALS AND METHODS}

All procedures were performed according to protocols and guidelines approved by the UNAM University Animal Care Committee. Mice (P30-P35) were decapitated, the brain was rapidly removed, and placed in ice-cold high sucrose artificial CSF (ACSF) solution (in mM: 252 sucrose, $3 \mathrm{KCl}, 2 \mathrm{MgSO}_{4}, 24 \mathrm{NaHCO}_{3}, 1.25$ $\mathrm{NaH}_{2} \mathrm{PO}_{4}, 1.2 \mathrm{CaCl}_{2}$ and 10 glucose) and bubbled with carbogen $\left(95 \% \mathrm{O}_{2}\right.$ and $\left.5 \% \mathrm{CO}_{2}\right)$. The cerebellum and frontal cortex were removed with a razor blade, and the hemispheres were separated and allowed to recover for 2-3 min in the oxygenated sucrose solution. Hippocampal isolate was then removed from the remaining hemisection as described previously ${ }^{[3]}$. 
After dissection, the hippocampal complex was left at room temperature in ACSF and bubbled with carbogen for $60 \mathrm{~min}$. For recording, the preparation was transferred quickly to a custom-made submerged recording chamber. Recordings were performed at $30-32{ }^{\circ} \mathrm{C}$ after an additional $30 \mathrm{~min}$ period acclimatization in the chamber. The preparation was continuously perfused with ACSF (25 ml/min, in mM: $126 \mathrm{NaCl}, 24 \mathrm{NaHCO}_{3}$, 10 glucose, 4.5 $\mathrm{KCl}, 2 \mathrm{MgSO}_{4}, 1.25 \mathrm{NaH}_{2} \mathrm{PO}_{4}$, and $2 \mathrm{CaCl}_{2}, \mathrm{pH} 7.4$, with $95 \% \mathrm{O}_{2} / 5 \% \mathrm{CO}_{2}$ ) via a gravity-fed perfusion system and maintained at $30^{\circ} \mathrm{C}$. Local field potentials were recorded using glass micropipettes (2 - $6 \mathrm{M} \Omega$ ) filled with ACSF. Signals were recorded through a differential AC amplifier (A-M Systems), filtered online $(0.1-500 \mathrm{~Hz})$, and sampled at $10 \mathrm{KHz}$. All drugs came from aliquots of stock solutions (stored at $-70{ }^{\circ} \mathrm{C}$ ) and were added to the perfusing artificial ACSF at the concentrations indicated. Pairwise comparisons between animals were performed with statistical analysis two sample $t$-test.

\section{RESULTS}

\section{Cholinergic agonist carbachol causes increase in the power of hippocampal theta activity}

The effects of the cholinergic agonist carbachol in the hippocampal theta activity were investigated by adding 1 $\mu M$ to our septo-hippocampal preparation with subsequent recording of the CA1 hippocampal area (Figure 1a). At baseline, the oscillations registered were in the range of theta band frequency, between 2 and $6 \mathrm{~Hz}$ (Figure 1a, 1b y 1c). During drug stimulation, the power of theta band activity increased as seen in the spectrogram analysis (Figure 1c). Filtered traces revealed the increment in theta power during stimulation (Figure $1 \mathrm{~b}$ and $1 \mathrm{c}$ ). The increase was further confirmed when the theta peak frequency was analyzed (Figure 1c and 1d). Interestingly, this increment in theta power was coupled to a reduction in theta frequency (Figure 1d). The behavior in frequency can be observed in the spectrogram analysis (Figure 1c) and the theta peak frequency analysis (Figure 1d).
Statistical analysis revealed that cholinergic stimulation with carbachol induces a $129.55+/-52.88$ increase in the percentage of theta power (Figure 1e) and no significant change in the theta frequency (data not shown).
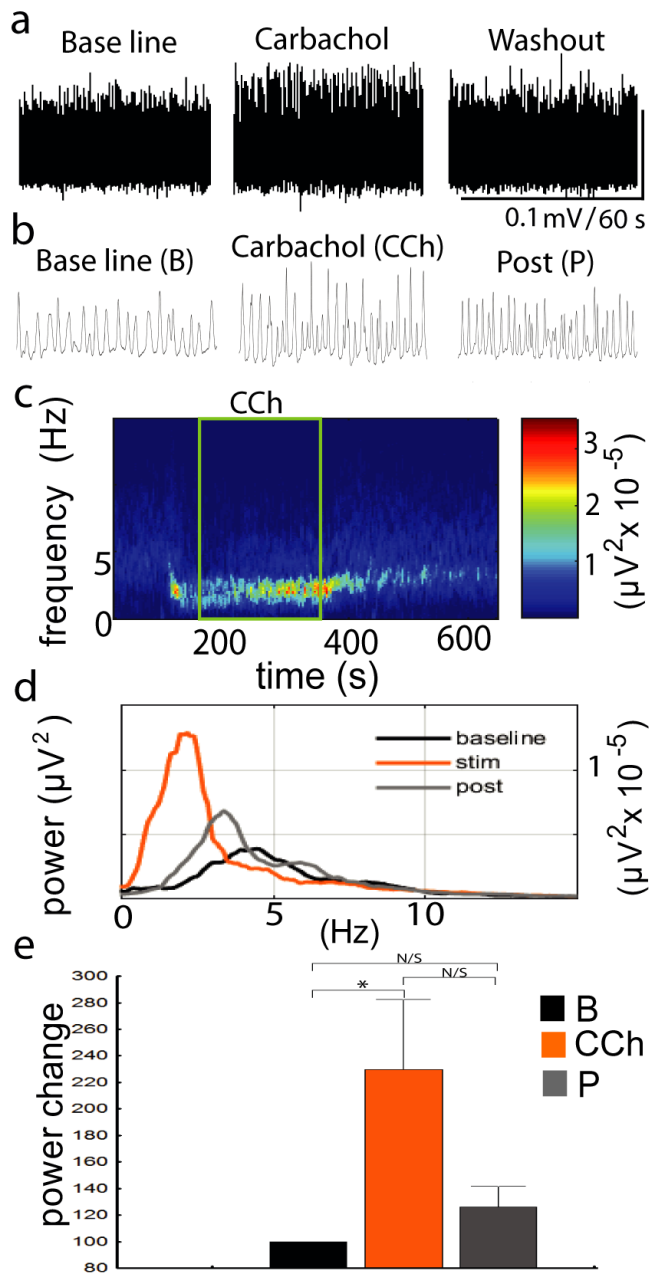

FIGURE 1. Effect of cholinergic agonist carbachol on hippocampal theta activity. Raw traces of the theta activity showing an increase in theta power during carbachol stimulation (a). Filtered traces before (B), during (CCh) and after (P) drug stimulation (b). Theta activity was recorded in the hippocampal CA1 area ( $a$ and $b$ ). Theta peak power analysis confirmed the power increase during drug treatment (c and d). Power spectrum analysis revealed the power increase during stimulation period ( $c$ and d). Statistical analysis of theta power after cholinergic stimulation (e). Relative theta power change before (B), during (CCh) and after (P) stimulation ( $n=5, p=0.039$, t-test). 


\section{Cholinergic agonist carbachol at elevated concentrations ( 2 - $5 \mu \mathrm{M})$ elicited a decrease in power of hippocampal theta activity}

Our data indicated increased power in theta activity with carbachol at concentrations of $1 \mu M$ (Figure 1). However, previous experiments were performed with carbachol between 5 and $10 \mu M^{[11]}$. In order to test this concentration in our septo-hippocampal preparation, we elevated carbachol concentration at higher doses (3 $-5 \mu M$ ) (Figure 2a). Here, our data indicate a drastic decrease in theta power activity, as seen in raw traces and spectrogram analysis (Figure $2 \mathrm{a}$ and $2 \mathrm{c}$ ). In order to investigate if the effect was mediated by muscarinic receptors, we applied scopolamine, an antagonist ${ }^{[10]}$. Changes in theta power were completely blocked by scopolamine addition (Figure $2 \mathrm{~b}$ ). The decrease is further confirmed when changes in theta peak power were analyzed (Figure 2d). Again, no detectable changes were observed in the frequency of the hippocampal theta activity (Figure 2c and 2d). Assuming, carbachol at elevated doses $(5 \mu M)$ could be in the proximity of the saturated response, we decided to evaluate it at $3 \mu M$. Here, our data indicate a similar effect in which the power of theta activity was decreased (data not shown). The statistical analysis confirmed our findings; carbachol at concentrations over $2 \mu M$ elicits a significant decrease in theta power activity (Figure 2e).

\section{Carbachol at lower concentrations (0.2 to $0.5 \mu \mathrm{M})$ causes decrease in power of hippocampal theta activity}

Our data indicated that carbachol at concentrations between 1 and $5 \mu M$ has an important effect on the power of hippocampal theta activity, increasing theta power at $1 \mu \mathrm{M}$ and decreasing it at concentrations over 2 $\mu M$ (Figure 1 and 2). With this in mind, we decided to test carbachol concentrations under $1 \mu M$ (0.2 to 0.5 $\mu M)$. It should be noted that carbachol at concentrations of $0.5 \mu M$ have been tested using in-vitro experimental approaches ${ }^{[12,13]}$. Surprisingly, our data showed that this
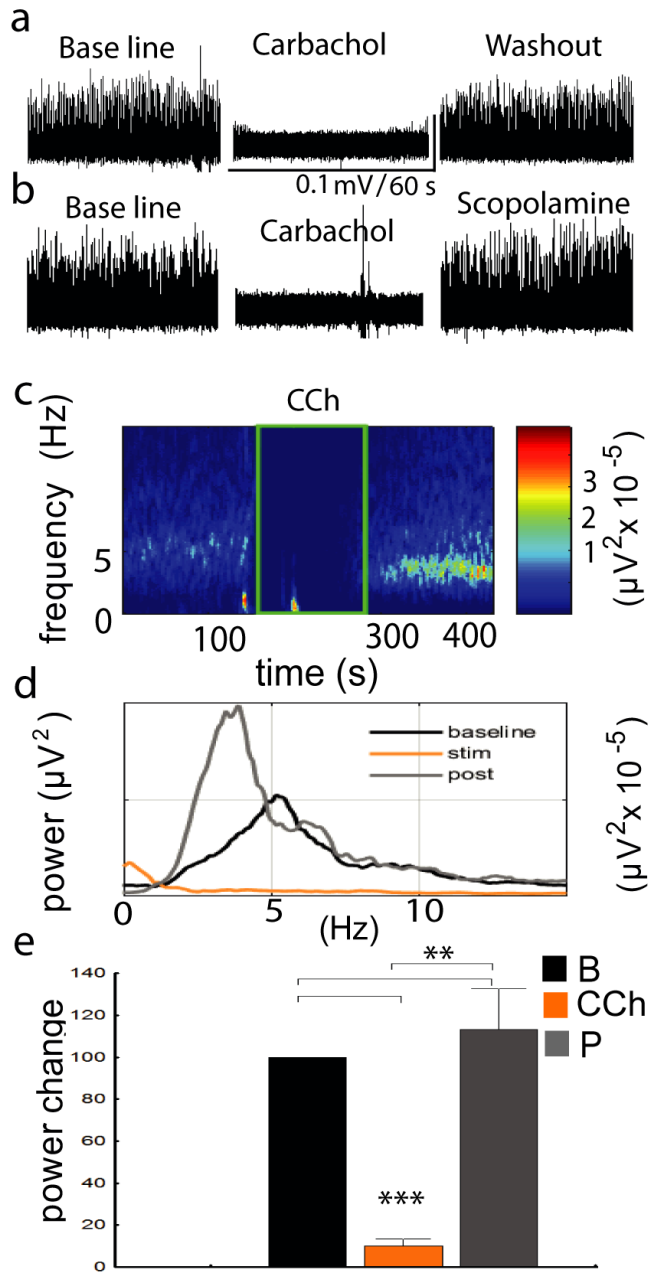

FIGURE 2. Effect of carbachol ( $2-5 \mu \mathrm{M})$ on hippocampal theta activity. Raw traces of the theta activity showing a decrease in theta power during carbachol stimulation (a). Theta power effect was completely blocked by scopol-

amine (b). Power spectrum analysis reveals a power decrease during stimulation period (c). Theta peak power analysis confirms the decrease in power during drug treatment ( $c$ and $d$ ). Theta peak frequency analysis before, during and, after carbachol stimulation (d). Statistical analysis of theta power after cholinergic stimulation (e). Relative theta power change before (B), during (CCh) and after (P) stimulation ( $n=7, p<0.001$, t-test).

particular concentration reduces the power of the hippocampal theta activity, as seen in the raw traces and spectrogram analysis (Figure 3a, $3 \mathrm{~b}$ and $3 \mathrm{c}$ ). The filtered traces also confirm changes in power of theta 
activity during drug stimulation (Figure 3b). The reduction is further confirmed when changes in theta peak power were analyzed (Figure 3d). Again, no detectable changes were observed in the frequency of the hippocampal theta activity (Figure 3c). The statistical analysis confirms our findings, carbachol at concentrations lower than $1 \mu M$ causes a significant decrease in theta power activity (e).

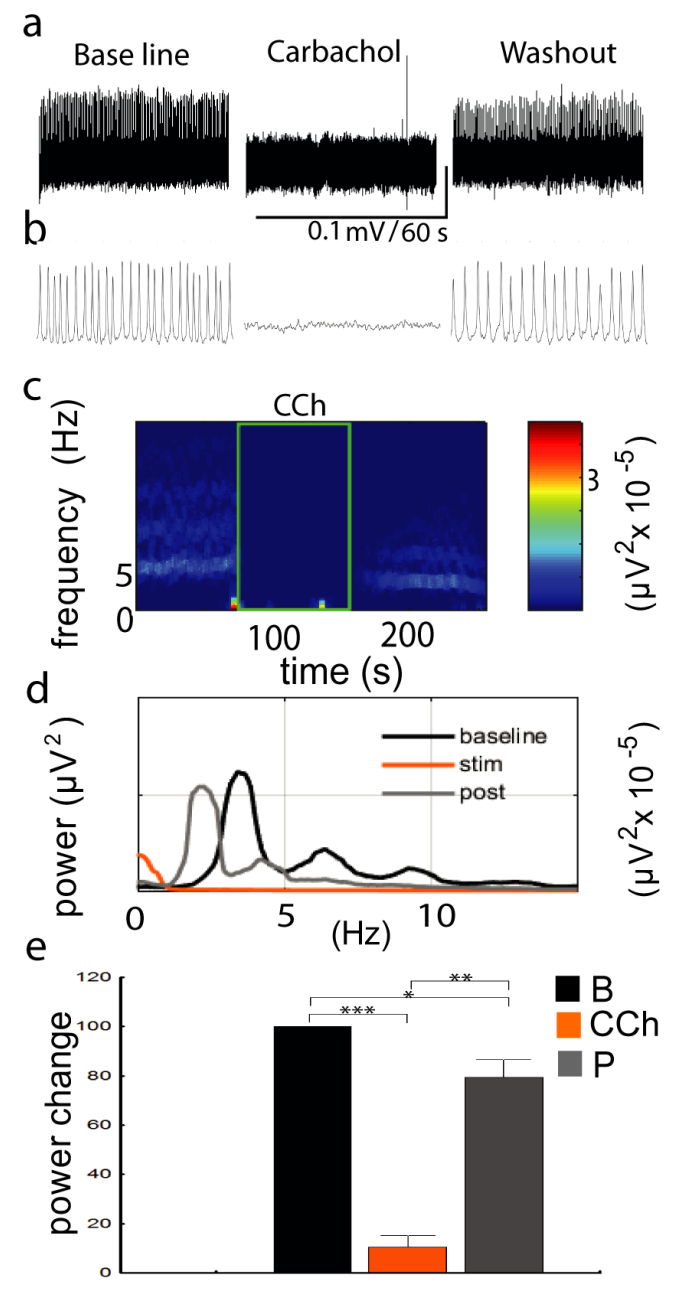

\section{DISCUSSION}

Is has previously been shown that there are two types of hippocampal theta activity, type I (atropine resistant or cholinergic independent) commonly associated with movement and, type II (atropine sensitive, cholinergic dependent) present when an animal is preparing to make movement ${ }^{[14,15]}$. In addition of being critical for integration of sensory information with motor output, theta activity has been correlated with spatial learning, navigation and is suggested to be critical for the induction of long term potentiation, a cellular mechanism of learning and memory ${ }^{[16]}$. Although theta activity can be seen in several brain structures, it is known that both types of theta activity can be strongly detected in the hippocampal formation ${ }^{[3]}$. Mechanistically, it was found that intraseptal microinfusion of carbachol resulted in continuous theta field activity regardless of what type of motor behaviour the animal performed or whether it was immobile ${ }^{[4]}$. Importantly, the performance of a voluntary movement resulted in an upward shift of theta frequency ${ }^{[4]}$. In contrariety, stimulation of cholinergic receptors in our septo-hippocampal preparation did not result in significant changes in theta frequency (Figure 1 and 2). In our case, the main difference was that we do not have all the inputs from another brain region i.e. entorhinal cortex, therefore

FIGURE 3. Effect of carbachol (0.2 - $0.5 \mu \mathrm{M})$ on hippocampal theta activity. Raw traces of the theta activity showing a decrease in theta power during carbachol stimulation (a). Filtered traces before, during and after drug stimulation (b). Power spectrum analysis reveals the power decrease during stimulation period (c). Theta peak power analysis confirms the decrease in power during drug treatment (c and d). Theta peak frequency analysis before, during and, after carbachol stimulation (d). Statistical analysis of theta power after cholinergic stimulation (e). Relative theta power change before, during and after stimulation $(n=6$, p $<0.001$, t-test).

our data contributes to dissecting the specific contribution of the septo-cholinergic pathway. Another important finding of intraseptal microinfusion of carbachol revealed enhancement of the hippocampal theta band ${ }^{[4]}$. This data has also been recently confirmed by Buszaky's group ${ }^{[7]}$. In agreement with this data, our cholinergic stimulation with carbachol at $1 \mu M$ resulted 
in a significant increase of hippocampal theta power (Figure 1). To rule out the possibility of unspecific responses, we blocked our effect with the antagonist scopolamine, and the observed changes in theta power were fully reversed (Figure 2).

Interestingly, when we used higher concentrations of carbachol (2-5 $\mu M)$ our recorded theta activity was drastically reduced (Figure 2). Again, no significant change was observed in the frequency of hippocampal theta activity (Figure 2). Initially we felt our results were due to a potential saturation effect; therefore, we decided to lower the carbachol concentration (0.2-0.5 $\mu M$ ) (Figure 3). Again, we observed a reduction in the hippocampal theta power with no detectable change in frequency (Figure 3).

Our data indicate that the concentration of the cholinergic agonist carbachol directly impacts in a dose-dependent manner the power of hippocampal theta activity. In agreement with published data, direct activation of the septo-cholinergic pathway resulted in direct modulation of hippocampal theta power. Additionally our data indicate positive or negative modulation of theta power can be achieved by different concentrations of cholinergic agonists. This data is of particular interest if we take into consideration that pharmacological activation of acetylcholine receptors with different molecules is a current proposed therapeutic strategy towards improvement of cognition in schizophrenia and Alzheimer's disease ${ }^{[17]}$. With this in mind, our data showed that proper receptor characterization towards hippocampal theta effect is critical when using and designing drugs directed to acetylcholine modulation.

\section{CONCLUSION}

In a complete septo-hippocampal preparation, carbachol elicited significant theta power enhancement with $1 \mu M$. Concentrations under $1 \mu M$ and over $2 \mu M$ carbachol caused significant reduction in the power of hippocampal theta activity.

\section{FINANCIAL \& COMPETING INTEREST'S DISCLOSURE}

The authors have no other relevant affiliations or financial involvement with any organization or entity with a financial interest in or financial conflict with the subject matter or materials discussed in the manuscript apart from those disclosed.

\section{ACKNOWLEDGMENTS}

The authors thank Francis A. M Manno III for critical comments. Work in the authors' laboratories is supported by the Canadian Institutes of Health Research (CIHR), Canada, and Fonds de la recherche en sante du QC (FRSQ), Quebec, Canada. Conacyt, DGAPA-UNAM and NIHGIZ-MD00791. This project was supported by a grant from Conacyt No. 269021. Siddhartha Mondragón-Rodríguez was awarded a Cátedra support from CONACYT, Mexico. 


\section{REFERENCES}

[1] Melonakos, E. D., White, J. A., \& Fernandez, F. R. (2016). Gain Modulation of Cholinergic Neurons in the Medial Septum-Diagonal Band of Broca Through Hyperpolarization. Hippocampus. doi: 10.1002/hipo.22653

[2] Sirota, A., \& Buzsaki, G. (2005). Interaction between neocortical and hippocampal networks via slow oscillations. Thalamus Relat Syst, 3(4), 245-259. doi: 10.1017/S1472928807000258

[3] Goutagny, R., Jackson, J., \& Williams, S. (2009). Self-generated theta oscillations in the hippocampus. Nat Neurosci, 12(12), 14911493. doi: $10.1038 / \mathrm{nn} .2440$

[4] Lawson, V. H., \& Bland, B. H. (1993). The role of the septohippocampal pathway in the regulation of hippocampal field activity and behavior: analysis by the intraseptal microinfusion of carbachol, atropine, and procaine. Exp Neurol, 120(1), 132-144. doi: 10.1006/ exnr.1993.1047

[5] Manseau, F., Goutagny, R., Danik, M., \& Williams, S. (2008). The hippocamposeptal pathway generates rhythmic firing of GABAergic neurons in the medial septum and diagonal bands: an investigation using a complete septohippocampal preparation in vitro. J Neurosci, 28(15), 4096-4107. doi: 10.1523/ JNEUROSCI.0247-08.2008

[6] Huh, C. Y., Goutagny, R., \& Williams, S. (2010). Glutamatergic neurons of the mouse medial septum and diagonal band of Broca synaptically drive hippocampal pyramidal cells: relevance for hippocampal theta rhythm. J Neurosci, 30(47), 15951-15961. doi: 10.1523/JNEUROSCI.3663-10.2010

[7] Buzsaki, G. (2005). Theta rhythm of navigation: link between path integration and landmark navigation, episodic and semantic memory. Hippocampus, 15(7), 827-840. doi: 10.1002/hipo.20113

[8] Vandecasteele, M., Varga, V., Berenyi, A., Papp, E., Bartho, P., Venance, L., .. . Buzsaki, G. (2014). Optogenetic activation of septal cholinergic neurons suppresses sharp wave ripples and enhances theta oscillations in the hippocampus. Proc Natl Acad Sci U S A, 111(37), 13535-13540. doi: 10.1073/pnas.1411233111

[9] Leszkowicz, E., Kusmierczak, M., Matulewicz, P., \& Trojniar, W. (2007). Modulation of hippocampal theta rhythm by the opioid system of the pedunculopontine tegmental nucleus. Acta Neurobiol Exp (Wars), 67(4), 447-460. doi:10.1016/i.brainresbull.2010.08.003.
[10] Masuoka, T., Fujii, Y., \& Kamei, C. (2006). Effect of scopolamine on the hippocampal theta rhythm during an eight-arm radial maze task in rats. Eur J Pharmacol, 539(1-2), 76-80. doi: 10.1016/j. e.phar.2006.03.046

[11] Fellous, J. M., \& Sejnowski, T. J. (2000). Cholinergic induction of oscillations in the hippocampal slice in the slow $(0.5-2 \mathrm{~Hz})$, theta (5-12 Hz), and gamma (35-70 Hz) bands. Hippocampus, 10(2), 187197. doi: 10.1002 (SICI)1098-1063(2000)10:2<187::AIDHIP08>3.0.CO;2-M

[12] Auerbach, J. M., \& Segal, M. (1996). Muscarinic receptors mediating depression and long-term potentiation in rat hippocampus. $\mathrm{J}$ Physiol, 492 ( Pt 2), 479-493. doi: 10.1113/jphysiol.1996.sp021323

[13] Yun, S. H., Cheong, M. Y., Mook-Jung, I., Huh, K., Lee, C., \& Jung, M. W. (2000). Cholinergic modulation of synaptic transmission and plasticity in entorhinal cortex and hippocampus of the rat. Neuroscience, 97(4), 671-676. http://dx.doi.org/10.1016/S03064522(00)00108-1

[14] Kramis, R., Vanderwolf, C. H., \& Bland, B. H. (1975). Two types of hippocampal rhythmical slow activity in both the rabbit and the rat: relations to behavior and effects of atropine, diethyl ether, urethane, and pentobarbital. Exp Neurol, 49(1 Pt 1), 58-85. http://dx. doi.org/10.1016/0014-4886(75)90195-8

[15] Sainsbury, R. S., Heynen, A., \& Montoya, C. P. (1987). Behavioral correlates of hippocampal type 2 theta in the rat. Physiol Behav, 39(4), 513-519. http://dx.doi.org/10.1016/0031-9384(87)90382-9

[16] Buzsaki, G., \& Chrobak, J. J. (2005). Synaptic plasticity and self-organization in the hippocampus. Nat Neurosci, 8(11), 1418-1420. doi: 10.1038/nn1105-1418

[17] Stoiljkovic, M., Leventhal, L., Chen, A., Chen, T., Driscoll, R., Flood, D., Hajos, M. (2015). Concentration-response relationship of the alpha7 nicotinic acetylcholine receptor agonist FRM-17874 across multiple in vitro and in vivo assays. Biochem Pharmacol, 97(4), 576-589. doi: 10.1016/j.bcp.2015.07.006 